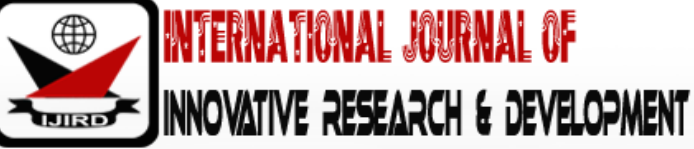

ISSN 2278 - 0211 (Online)

\section{Level of Social engagement of Pupils with Intellectual Disabilities in Unit School Setting: The Case of Adukrom Methodist Basic School, Ghana}

\author{
Philemon Amaniampong \\ Tutor, Department of Education, Methodist College of Education, Akim Oda, Ghana
}

\begin{abstract}
:
The purpose of the study was to explore the level of social engagement of pupils with intellectual disabilities at Adukrom Methodist Basic School in the Eastern Region of Ghana. The case study design was employed for the study. The sample size was 21, which comprised of teachers and pupils with and without intellectual disabilities. Interviews and an observation guide were used to collect data. The purposive sampling technique was used to select the sample size. Data from interviews was analyzed thematically while observation data was statistically analyzed. Results from the study showed that pupils with intellectual disabilities sometimes played together with their non-disabled peers; they made friends and maintained the friendship but others do not due to the behaviors of pupils with intellectual disabilities. It was also established that pupils with intellectual disabilities were averagely engaged in social activities in the school. It was recommended that Teachers should collaborate with other professionals to work on the behaviors of pupils with intellectual disabilities to enable them maintain their friendship with peers and also help them to play together always.
\end{abstract}

Keywords: Intellectual disabilities, social engagement, unit school, nondisabled peers

\section{Introduction}

The level of social engagement in this context means how a student with special educational needs (SEN) is liked by nondisabled peers, performs non-classroom activities together with nondisabled peers, and number of nondisabled friends they have. Other factors that influence social relationships are social position and level of interaction. Social relationship of students with SEN is an important aspect of studying inclusion in regular education (Flem \& Keller, 2000). Research has shown that the opportunity for contacts and interactions with regular peers is one of the main motives that parents have for sending their students with special needs to a regular school (Nakken \& Pijl, 2002) Many pupils with intellectual disabilities have low levels of social engagement and a dearth of friendship (Verdonschot DeWitte ReichrathBuntinx, \& Curfs, 2009). Also the stigma associated with their disability has often resulted in their active isolation from society (Akrami Ekehammar Claesson \& Sonnander, 2006) as in their exclusion from formal systems such as education and employment. This in turn reduces their opportunities for community interactions and friendships (Lippold \& Burns, 2009). Arguably, the provision of specialized services from early childhood onwards has further isolated people from their peers (McConkey, 2011), because studies indicate that children with intellectual disabilities tend to exhibit relatively low levels of involvement with other children during play, even under facilitative play conditions such as having regular playmates at their own home (Guralnick, Connor \& Johnson, 2009).

Gifford-Smith and Brownell (2003), argue that relationships and friendships with peers are related not only to social and behavioral development but also to students' academic achievement. They still argued that students with more friends have fewer adjustment problems, higher self-esteem, and report less loneliness, enjoy wider peer acceptance, display better school adjustment, positive attitudes toward school, in addition to better achievement. Peer acceptance is a measure of social position and is defined as the degree to which a pupil is accepted by his/ her peer group. It should be noted that peer group acceptance does not necessarily reflect mutual emotional bonds, which are studied on the relational level of enquiry (Rubin, Bukowski \& Parker, 2006). Low peer acceptance and peer rejection have been associated with a vast array of concurrent and future indicators of adaptation (Ladd, 2005).

The relevant issue concerns the co-occurrence of actual and perceived social inclusion that is how group and individual phenomena are related. Loneliness has often been seen as an outcome of negative experiences with peers, and certainly, reports of loneliness have been found to be more likely among children who are poorly accepted (Shin, 2007). The experiences of members of Children with Disability Australia (CDA) overwhelmingly suggests that students and their peers struggle to bridge a gulf between accepting the presence of students with disabilities at school and valuing their membership as part of the school community (Prince \& Hadwin, 2013). 
A study conducted in Italy about the social position and inherent sense of belonging of students aged 8-11 years old (Nepi, Facondini, Nucci, \& Peru, 2013) found that, while students without disabilities indicated positive attitudes, students with disabilities did not feel a similar sense of belonging. They attributed this to a 'compassionate biases on the part of higher achieving students. In another study, Bunch and Valeo (2004) sampled the views of peers of students with disabilities in Canada, and found that non-disabled high school students held a consistent view that students with disabilities had friends, but that their friends were other students with disabilities, and their friendships were maintained in their own separate classroom or social space within the school. This study revealed that grouping and special treatment of students with disabilities acted as a barrier to relationships, that social and academic separation existed between students with and without disabilities, and that instances of friendship between students with and without disabilities were limited to early elementary school level.

A study by Frostad and Pijl (2007) about Norwegian inclusive classrooms revealed that, $20 \%$ to $25 \%$ of students with special education needs (SEN) were not socially included in their peer group, and nearly $25 \%$ of pupils with special needs had serious difficulties forming relationships in their peer group, while only about $8 \%$ of their non-SEN peers' problems with developing relationships. Several studies have found that within the group of pupils with special needs, pupils diagnosed as having autistic spectrum disorders and pupils diagnosed as having serious behavioural disorders find it particularly difficult to build relationships with typical peers, and are at risk of becoming isolated in the classroom (Chamberlain, Kasari, \& Rotheram-Fuller, 2007; De Monchy, Pijl \& Zandberg, 2004). Nowicki (2006) also found that pupils diagnosed as having intellectual disabilities are also at risk of isolation in the classroom. Furthermore, most were unwilling to socially interact with a student with an intellectual disability in "friend type" activities (e.g., nondisabled student inviting a student with an intellectual disability to spend time with his/ her friends).

Another study was conducted by Siperstein, Glick and Parker (2009) on social inclusion of children with intellectual disabilities in a recreational setting. In that study, social acceptance of children with and without intellectual disabilities was examined. Participants were 67 children entering Grades 3 through 6, of which 29 were identified as having a mild intellectual disability. The children were recruited from economically and racially diverse urban school districts. Results showed that children with and without intellectual disabilities were equally accepted by their peers. Specifically, 95\% of children without intellectual disabilities indicated that they liked to "hang out with" at least 1 child with an intellectual disability. Results also indicated that the majority of children without intellectual disabilities made at least one new friend with another child with an intellectual disability. The above discussed reasons informed the researcher to investigate the level of social engagement of pupils with intellectual disabilities at Adukrom Methodist Basic School in the Eastern Region of Ghana.

\section{Methodology}

Case study research design as well as qualitative method as an approach were used for the study. When it goes to the choice of the sources of data qualitative, researchers prefer multiple methods. This helps to develop a complex picture of the problem and identify complex interactions and larger pictures of the issue. This explains why qualitative data was chosen to help answer the research problem; namely, level of social inclusion of pupils with intellectual disabilities at unit school setting. The study therefore limited its scope to investigating the phenomena oflevel of social inclusion of pupils with intellectual disabilities at Adukrom Methodist Basic School in the Eastern Region of Ghana.

The sample size for the study was 21. This consisted of 5 teachers ( 3 males and 2 females), 16 pupils ( 8 pupils with intellectual disabilities and 8 without intellectual disabilities). Out of the pupils without intellectual disabilities, 4 were girls and 4 were boys; while out of pupils with intellectual disabilities, 2 were girls and 6 were boys. The 8 out of 12 pupils with intellectual disabilities were chosen based on their ability to speak and their regular school attendance.

Semi structured interview and structured observation were employed to elicit data from the participants for the study. O'Leary (2005), indicated that semi-structured interviews are neither fully fixed nor fully free and are perhaps best seen as flexible in gathering qualitative data. The researchers used semi-structured interview approach because it offers interviewee the opportunity to express their views, feelings and experiences freely and the interviewer the freedom to divert the questions in the schedule to seek clarifications (Cohen, Manion \& Morrison, 2004). A structured observation according to Bryman (2005), entails the direct observation of individuals in field settings and the recording and encoding of observations according to a previously formulated schedule. The researcher developed an observation checklist as a guide in recording relevant facts, actions and behaviours of participants concerning the research problem. The researcher was assisted by two teachers in the school in gathering an interpreting observation data.

\subsection{Procedure for Data Collection}

Informed consent was obtained from the authorities of the school prior to the commencement of the study. This was facilitated by an introductory letter formally submitted to the head teacher of the school indicating the purpose of the study. A familiarization visit was done to the school to book appointments with school authorities, teachers and pupils. The appointments were made such that it was possible to meet pupils and teachers that were involved in the study. In addition to the letter, the researcher explained the purpose of the study to the participants and informed them that the finding of the study was purely an academic work. And further explain why their school was chosen and detailed how much time would be spent at the school. They were duly informed that their participation was voluntary and were free to abstain or even withdraw from the study, if they felt so.

The interview was conducted within the school premises using a semi-structured interview guide. The main procedure for conducting the interviews was through the use of tape recorders and each interview lasted between 10 to 15 minutes. 
With this, the teachers and the pupils were assured the necessary confidentiality throughout and permissions were sought to use a tape-recorder.

In the case of the observation component, the researcher and teachers of each class observed the pupils in and out of class, especially during break times and other social activities. Each class teacher observed and took notes on interactions among the pupils for the first week (baseline data). An observation checklist was used to collect the data. It contained items organized in a Likert scale with "Yes", "No" and "Not certain". The items included how regular pupils behaved towards their peers with intellectual disabilities. (e.g., looked frightened at them, bullied them, played with them, ate with them, borrowed items from them, make friends with them, and so on).

\subsection{Data Analysis}

Analysis of the semi-structured interview data was guided by key themes that emerged from the data collected. The process started with transcribing all interview data and highlighting words, sentences, and thoughts that served as units for more detailed coding. The analysis primarily involved an interactive process of reading, reflecting, and coding the transcripts, and then drawing out major themes and patterns of views from it. With the observation component, the researcher met with other two observers who were teachers in the school to analyze the data. An inter-observer agreement was determined by calculating the percentage of agreement between the researchers' observation and that of other observers. The researchers asked the other observers to react to the observation data by indicating whether the observation instrument used generated an accurate picture of level of social inclusion of pupils with intellectual disabilities or not.

\section{Findings and Discussion}

To answer the problem posed, the interview data collected from the teachers were used. Teachers' responses were grouped according to the level of social engagement of pupils with intellectual disabilities in the school.

\subsection{Playing Together with Their Peers}

Per the level of engagement of pupils with intellectual disabilities, the interaction with the teachers revealed that pupils with intellectual disabilities and their peers sometimes play together. A remark made by a teacher attested to this: I will say their level of involvement is average because it is not every activity that they are being involved. When it comes to worship, they are involving by sometimes leading the songs and when it comes to sports festivals they don't take part in the active sports but during break time and Fridays they play together in both indoor and outdoor games. (A verbatim response from teacher ' $\mathrm{A}$ ')

Another teacher said this:

For the level of social inclusion is not the best of it but is ok. Looking at morning assembly, they are part, worship they are part, it is only sports that they don't involve them because, their kind of sports is different. When it comes to sweeping or cleaning of compound some of them are not involved due to their condition but for their classroom they sweep it and wash their bowls themselves. In terms of playing, they play with their peers during break time and run after each other. (A verbatim response from teacher ' $\mathrm{B}$ ')

we normally play together in the morning, afternoon and during the break periods. (A verbatim response from pupil with intellectual disabilities '1')

Another pupil with intellectual disabilities remarked this way.

We play together, we play football, and we also go to assembly together. During worship too, the teachers do come to teach us songs, direct us to sit well and also guide us when we are playing. (A verbatim response from pupils with ID '2').

Two pupils without intellectual disabilities also stated this way.

Yes, we do involve them, when we are playing, they come there to take part. Not always because, sometimes they go for break before us and it is not all the games that they can play.

. they are involved in games like "ampe" "pilolo", netball we also go to assembly and worship together during Wednesdays

(A verbatim response from pupils without ID).

From the views of the teachers and the pupils with and without intellectual disabilities, it was established that the pupils with intellectual disabilities sometimes play together with their peers. This is consistent with Guralnick et al. (2009) and Avramadis (2012) who indicated that children with intellectual disabilities play with their peers but tend to exhibit relatively low levels of involvement with other children during play, even under facilitative play conditions such as having regular playmates at their own home.

\subsection{Peer Acceptance}

On peer acceptance, the teachers indicated that pupils without disabilities accept their peers with intellectual disabilities though they sometime find it difficult to cope with them. His comment went this way;

Their friends do accept them but sometimes they are more careful because some of the pupils with intellectual disabilities are hyperactive and their hyperactivity is so high that they sometimes throw stones at their peers or behave abnormally towards them. (A verbatim response from teacher ' $C$ ')

Another teacher remarked this way;

They do accept them during break time you will see them playing together, running, jumping and throwing of items. They don't differentiate against them for having disabilities. (A verbatim response from teacher 'A')

The interview I conducted with the pupils also showed that pupils without intellectual disabilities accept their peers with intellectual disabilities. Two pupils with intellectual disabilities acknowledged that: 
Our peers without intellectual disabilities too accept us as their friends. The teachers also accept us, they teach us give us work and also guide us when we are playing and singing

Our peers without intellectual disabilities don't laugh at us and they don't beat or treat us bad when playing with them (A verbatim response from pupils with IDs).

From the perspective of all the teachers interviewed, pupils without disabilities do accept peers with intellectual disabilities and it was confirmed by some of the pupils. Which is in agreement with Bunch andValeo (2004) who sampled the views of peers of students with disabilities in Canada, and found that non-disabled high school students held a consistent view that students with disabilities had friends, but that their friends were other students with disabilities, and their friendships were maintained in their own separate classroom or social space within the school again, Siperstein, Glick and Parker (2009. revealed that children with and without intellectual disabilities were equally accepted by their peers. Specifically, 95\% of children without intellectual disabilities indicated that they liked to "hang out with" at least 1 child with an intellectual disability. Results also indicated that the majority of children without intellectual disabilities made at least one new friend with another child with an intellectual disability but in disagreement with Frostad and Pijl (2007) reported findings from a study in Norway similar to those of the present study. Specifically, the study in Norway also found that students with disabilities and those with behavior problems had considerably more difficult times finding and keeping friends. Similar conclusions were found in three studies from the United States (Kuo et al., 2011; Matheson et al., 2007; Tipton et a., 2013) that teenagers with cognitive disabilities and autism had simpler notions of friendship than other teenagers.

\subsection{Maintenance of Friendship}

On maintenance of friendship, the data analysis revealed that some of the pupils were able to maintain their friendship but others were not due to their behaviors. One of the teachers stated this way.

maintaining the friendship, when they come to school and they meet their friends, they greet them, talk to them and the mainstream pupils don't avoid them although some of the pupils with intellectual disabilities have a lot of problems. Their friends sometimes come to their class here to chat with them. (A verbatim response from teacher ' $\mathrm{B}$ ').

Concerning the issue of maintenance of friendship, there were mixed reaction, while some of the teachers said the pupil maintained it through greetings and regular visit other were having different view that, they find it difficult to maintain friendship. But the pupils were silent about this because they find it difficult to understand. Robinson and Truscott (2013) corroborates this finding when they stated that making and maintaining friendships is a primary theme that emerges as critical to a sense of belonging in school for students with disabilities.Anderson et al. (2011) interviewed the non-disabled friends of children who communicated via augmentative and alternative communication (AAC) and had cerebral palsy, to find out about their experiences of friendship. The children described mutually beneficial friendships, through language such as 'he cares about me and I care about him' (p.82). Although, the friendships had arisen spontaneously between the children through common interests, altruism, recognition and positive feedback were motivators for the children without disabilities to maintain their relationship. This study disagreed with Chamberlain, Kasari, \& Rotheram-Fuller, 2007; De Monchy, Pijl \& Zandberg, 2004). Nowicki (2006) who have found that within the group of pupils with special needs, pupils diagnosed as having autistic spectrum disorders and pupils diagnosed as having serious behavioural disorders find it particularly difficult to build relationships with typical peers, and are at risk of becoming isolated in the classroom

Moreover, data gathered from observation confirmed the response of the participants revealing thatpupils with intellectual disabilities in most cases play together, their friends accept them, some maintain their friendships but others find it difficult to maintain their friendship. It also shows that pupils with intellectual disabilities were averagely involved in social activities.

\section{Conclusion and Recommendation}

It was concluded that pupils with intellectual disabilities sometimes played together with their non-disabled peers; they made friends and maintained the friendship but others did not maintain the friendship due to the behaviors of pupils with intellectual disabilities. It was also established that pupils with intellectual disabilities were averagely engaged in social activities in the school.Based on the conclusion, it was recommended that Teachers should collaborate with other professionals to work on the behaviors of pupils with intellectual disabilities to enable them maintain their friendship with peers and also help them to play together always.

\section{References}

i. Akrami, N., Ekehammar, B., Claesson, M., \& Sonnander, K. (2006) Classical and modern prejudice:attitudes towards people with intellectual disabilities. Research in Developmental Disabilities, 27, 605-17.

ii. Anderson, K., Balandin, S., \& Clendon, S. (2011). "He cares about me and I care about him:" Children's experiences of friendship with peers who use AAC. Augmentative and Alternative Communication, 27(2), 77-90.

iii. Avramidis, E. (2012). Self-concept, social position and social participation of pupils with SEN in mainstream primary schools. Research Papers in Education, 1-22.

iv. Bunch, G., \& Valeo, A. (2004). Student attitudes toward peers with disabilities in inclusive and special education schools. Disability \& Society, 19(1), 61-76.

v. Bryman, A. (2005). Social research methods. Canada: Oxford University Press.

vi. Chamberlain, B., Kasari, C. \& Rotheram-Fuller, E. (2007). Involvement or acceptance, friendships, and peer networks. Journal of School Psychology 41, 235-284

vii. Cohen, L. Manion, L. \& Morrison, K. (2004). Research methods in education. (6th Ed.). Routledge: New York. 
viii. De Monchy, M., Pijl, S. J. \& Zandberg, T. J. (2004). Discrepancies in judging social inclusion and bullying of pupils with behavior problems. European Journal of Special Needs Education, 19(3), 317-330.

ix. Flem, A., \& Keller, C. (2000). Inclusion in Norway: A study of ideology in practice. European Journal of Special Needs Education, 15(2), 188-205.

x. Frostad, P. \& Pijl, S. J. (2007). Does being friendly help in making friends? The Exceptional Children, 68 (4), 503-5

xi. Gifford-Smith, M. E., \& Brownell, C. A. (2003). Childhood peer relationships: Social acceptance, friendships, and peer networks. Journal of School Psychology, 41,235-284.

xii. Guralnick, M. J., Connor, R. T., \& Johnson, C. L. (2009). Home-based peer social networks of young children with Down syndrome: A developmental perspective. American Journal on Intellectual and Developmental Disabilities, 114(5), 340-355. Do i:10.1352/ 1944-7558-

xiii. Kuo, M. H., Orsmond, G. I., Cohn, E. S., \& Coster, W. J. (2011). Friendship characteristics and Korean primary school children. School Psychology International, 28, 220-236.

xiv. Ladd, G. W. (2005). Children's peer relations and social competence: A century of progress. New Haven, CT: Yale University Press.

xv. Lippold, T., \& Burns, J. (2009) Social support and intellectual disabilities: a comparison between social networks of adults with intellectual disability and those with physical disability. Journal of Intellectual Disabilities Research, 53, 463-73.

xvi. (16) Matheson, C., Olsen, R. J., Weisner, T., \& Dykens, E. (2007). A good friend is hard to find: Friendship among adolescents with disabilities. American Journal on Mental Retardation, 112(5), 319-329.

xvii. McConkey, R. (2011). Leisure and friendships. In H. Atherton, \& D. Crickmore Edinburgh: Churchill-Livingstone. (Eds.), Learning disabilities: Towards inclusion (6 ${ }^{\text {th }}$ Ed.) (pp. 431-47).

xviii. Nakken, H., \& Pijl, S. J. (2002) Getting along with classmates in regular schools: a review of the effects of integration on the development of social relationships. International Journal of Inclusive Education, 6 (1) 47-61.

xix. Nepi, L. D., Facondini, R, Nucci, F., \& Peru, A. (2013). Evidence from full-inclusion model: The social position and sense of belonging of students with special educational needs and their peers in Italian primary school. European Journal of Special Needs Education, 2, 1-14.

xx. Nowicki, E. (2006). A cross-sectional multivariate analysis of children's attitudes toward disabilities. Journal of Intellectual Disability Research, 50 (5), 335-348.

xxi. O, Leary, Z. (2005). Researching real-world problems: A guide to methods of inquiry. London: Sage Publications.

xxii. Prince, E. J., \& Hadwin, J. (2013). The role of a sense of school belonging in understanding the programs. Title 92, Nebraska Administrative Code, Chapter 51.

xxiii. Robinson, S., \& Truscott, J. (2013). Belonging and connection of school students with disability issues paper. Sydney: Children with Disability Australia.

xxiv. Rubin, K. H., Bukowski, W. M. \& Parker, J. G. (2006). Peer interactions, relationships, and groups. In W. Damon,

xxv. R. M. Lerner, \& N. Eisenberg (Eds.), Handbook of child psychology: Social, emotional, and personality development (6th ed., pp. 571-645). Hoboken, NJ: Wiley. 3 (6) 571-645

xxvi. (xxv)Shin, Y. (2007). Peer relationships, social behaviours, academic performance and loneliness in Korean primary school children. School Psychology International, 28, 220-236.

xxvii. (xxviSiperstein, G. N., Glick, G. C., \& Parker, R. C. (2009). On social inclusion of children intellectual disabilities in a recreational setting. American Association on Intellectual and Developmental Disabilities, 47(2), 97-107.

xxviii. (xxvii)Tipton, L. A., Christensen, L., \& Blacher, J. (2013). Friendship quality in adolescents with and training for students with high-incidence disabilities. Exceptional Children, 67(3), 331-344.

xxix. (xxviii)Verdonschot M. M. L., de Witte L. P., Reichrath E., Buntinx W. H. E. \& Curfs L. M. G. (2009) Communityparticipation of people with an intellectual disability: a review of empirical findings. Journal of Intellectual Disability Research, 53,303-18. 